marine stratigraphic sequences. Thus, an ash layer forms a tightly defined time-marker.

One of the perennial problems of working in bog and lake deposits is correlation from one core to another. Analyzing tephra can be an ideal technique in these circumstances, since the horizontal layers are so sharply defined.

\section{Tephra as a Taphonomic Guide}

Tephra has so far been under-utilized as a taphonomic guide. As the tephra fall is assumed to occur at least within a single year, we can make a good assessment of post depositional processes by looking at the vertical spread of the tephra in a sediment core. Spreading can also be the result of delayed deposition of particles stored for more or less time in the watershed or the lake basin. As the particle size of the typical tephra layer is of the same order as that of pollen, for example, it can suggest the extent to which pollen and other micro- fossils may have been moved vertically in the sediment profile. For example, if the tephra were spread over $5 \mathrm{~cm}$, there would be little point in undertaking a pollen study at a resolution of $1 \mathrm{~cm}$.

\section{Tephra as a Chronology}

Tephrochronology consists of knowing when eruptions took place and then of tying a tephra fall to a particular eruption by its chemistry. From about AD 1100, a well-recorded chronology of calendrical accuracy exists for Iceland. Before settlement in Iceland, we are dependent on dating tephra layers by independent means. Radiocarbon dating of a terrestrial peat allows a precise date to be applied to tephra-bearing low-organic lake sediments or marine to brackish water sediment that is unsuitable for precision radiocarbon dating. One of the ongoing projects is to use the calendrical precision of the new NGRIP Greenland ice core to produce dates for the geochemically typed tephra layers it contains.

\section{AcKnOWLedgements}

The Lofoten Islands project is supported by a National Science Foundation grant (Paleoclimatology Program) to the University of Massachusetts.

\section{REFERENCES}

van den Bogaard, P. and Schminke, H.-U., 2002: Linking the North Atlantic to central Europe: a high resolution Holocene tephrachronological record from northern Germany. Journal of Quaternary Science 17: 3-20.

Haflidason, H., Eiriksson, J. and van Kreveld, S., 2000: The tephrochronology of Iceland and the North Atlantic region during the Middle and Late Quaternary: a review. Journal of Quaternary Science 15: 3-22.

Hall, V.A. and Pilcher, J.R., 2002: Late quaternary Icelandic tephras in Ireland and Great Britain: detection, characterization and usefulness. The Holocene 12: 223-230.

Larsen, G. and Thorarinsson, S., 1977: H4 and other acid tephra layers. Jokull 27: 29-47.

Pilcher, J.R., Hall, V.A. and McCormac, F.G., 1996: An outline tephrochronology for the north of Ireland. Journal of Quaternary Science 11: 485-494.

For full references please consult: www.pages-igbp.org/products/newsletters/ref2003_2.htm

\title{
Simulating the Climate of the Last Millennium
}

\author{
Martin Widmann ${ }^{1}$ and Simon F.B. Tetr ${ }^{2}$ \\ ${ }^{1}$ Institute for Coastal Research, GKSS Research Centre, Geesthacht, Germany; widmann@gkss.de \\ ${ }^{2}$ Hadley Centre for Climate Prediction and Research, Met Office, Bracknell, UK; simon.tett@metoffice.com
}

\section{Introduction}

Climatic changes during the last thousand years have received great interest. Uncertainty in climate reconstruction is smaller than in earlier periods and the external forcing factors of the climate system are relatively well known, making comparisons with 20th century climate well suited to assessing the influence of human activities. Numerical modelling complements the efforts to reconstruct past climates from proxy records. The goals of paleoclimate modelling are to reduce uncertainties in climate reconstructions through consistency tests with evidence from proxy data, to validate climate models, to provide hypotheses on the climatic evolution at locations or variables not covered by proxy data, and to improve process understanding. The latter should include distinguishing be- tween internal variability and the effects of varying external forcings, and understanding feedback mechanisms.

\section{Types of Climate Models and Simulations}

The simplest climate models are zero- or one-dimensional energy balance models (EBMs), which have low computational costs and clear links between simulated processes and climate. At the other end of the spectrum are quasi-realistic, computationally expensive, general circulation models (GCMs), which usually feature sub-models for the atmosphere, the ocean and the sea ice on 3-dimensional grids with typical horizontal spacings of a few hundred kilometers and 15-100 vertical levels. GCM components for the carbon cycle, chemical processes, land ice and vegetation dynamics are currently under development. In between EBMs and GCMs are a variety of models with varying numbers of dimensions and complexity, for instance, earth system models of intermediate complexity (EMICs), which describe the atmosphere and ocean dynamics in less detail but which place more emphasis on the role of vegetation and chemical processes in the climate system. Climate models are mainly used in two different ways. In equilibrium experiments, the forcing factors for the climate system, such as solar irradiance, the atmospheric composition, or the earth's orbit, are held constant but may vary between different runs. These simulations represent the mean climate and the statistics of internal climate variability. Transient, forced simulations also include the climate response to time-varying forcings using historical estimates. 


\section{Global Mean Temperature Difference from 1550 - 1800 Average}

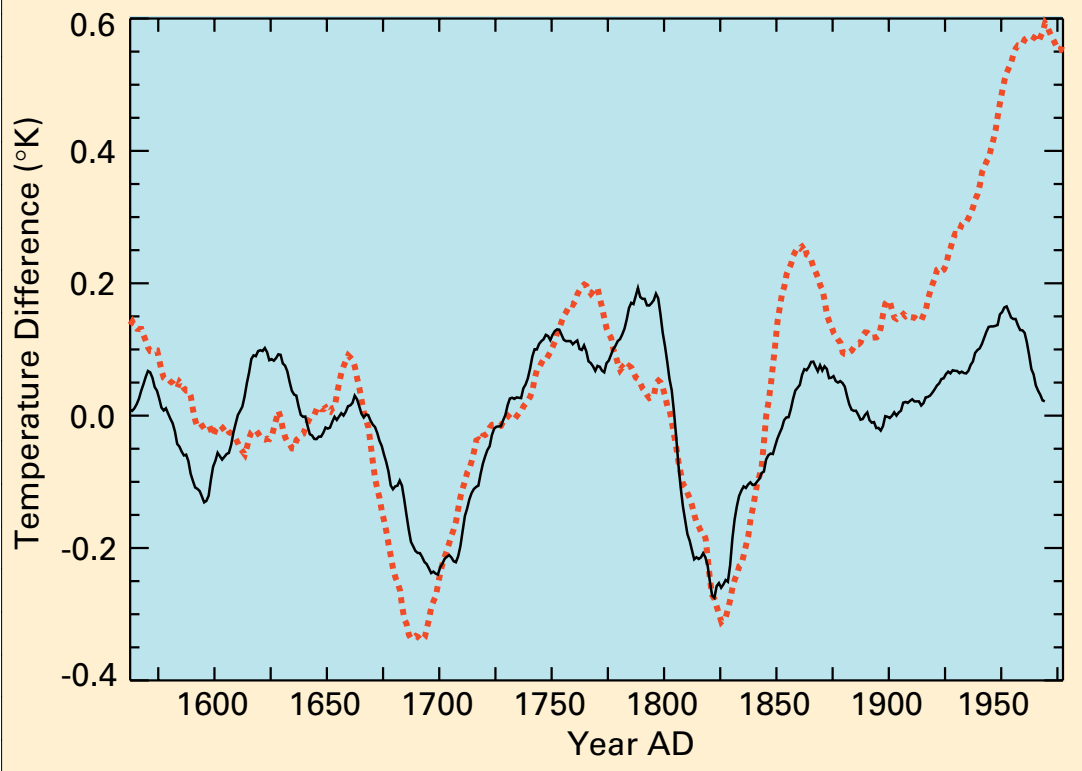

Figure 1:Time series of global-mean temperature. Shown are time series of global-mean temperature from ECHO-G (solid black line) and HadCM3 (dashed red line) simulations. Note that ECHO-G was forced with natural and anthropogenic simulations while HadCM3 was driven only by natural forcings. Both simulations are shown as differences relative to the 1550-1800 average and represent a 25-year running average.

Since the evolution of the climate system is not completely determined by external forcings but also contains a stochastic component, even a perfect model with all forcing mechanisms included will yield only one out of many possible climate realizations consistent with the forcings. This realization will be different from the realization that took place in the real world. Therefore any comparison between model and reconstruction will be probabilistic in nature.

\section{Results}

By the mid-1990s, coupled GCM equilibrium experiments for preindustrial conditions were typically around 100 years long but the first runs with lengths of about 1000 years became available at some modelling centers (GFDL, MPI and UKMO). These simulations were used, for instance, to clarify the roles of the atmosphere and the ocean in generating internal climate variability (Manabe and Stouffer, 1996), or to estimate natural variability, the basis for detection and attribution of climate change (Hegerl et al., 1996). However, the agreement among models on the spatial structure and magnitude of natural variability was only moderate and deviations from observations became evident (Barnett, 1999). A very long simulation of 15000 years using the GFDL model with a relatively low resolution suggested that large-scale, multi-decadal temperature anomalies with very strong amplitudes of about 6-10 standard deviations could be generated merely by internal processes (Hall and Stouffer, 2001). Recently, 1000-year-long equilibrium runs with higher resolutions (about $300 \mathrm{~km}$ ) were conducted at UKMO (Collins et al., 2001) and MPI. Because they are much longer than the instrumental climate record, they are well suited to test paleoclimatic reconstruction methods on decadal to centennial time-scales (Zorita and GonzálezRouco 2002, Zorita et al. 2003).

Many transient simulations begin in the middle of the 19th century to investigate the climatic effects of anthropogenic greenhouse gases and aerosols (e.g. Stott et al., 2000). The climatic response to changing solar forcing was investigated with a coupled GCM forced by estimates for solar variability from 1700 to the present (Cubasch et al., 1997). The spatial pattern associated with solar forcing was found to be similar but not identical to the signal of changing greenhouse gas concentrations. The pronounced insolation decrease during the Dalton Minimum (DM) around 1820 caused global cooling. Some of the recent work focuses on the Late Maunder Minimum (LMM). A transient simulation with an EBM forced by solar and volcanic activity, anthropogenic greenhouse gases and aerosols produced a global temperature well correlated with proxy reconstructions (Crowley, 2000); in particular a cooling during the LMM was found. A LMM cooling was also found in a 1000-year-long run with a two-dimensional zonally averaged atmosphere-ocean model (Bertrand et al., 2002). It should be noted, however, that the climate sensitivity to changes in the forcing can be tuned in both models. A 1000-year-long run with an EMIC (Bauer et al., 2003) used similar forcings but also information on deforestation. Northern Hemisphere temperatures correlated well with proxy reconstructions. During the LMM and the DM, pronounced cooling took place due to solar and volcanic forcing. During the last half of the 19th century, deforestation led to cooling.

Shindell et al. (2001) used equilibrium runs of an atmospheric GCM with detailed ozone chemistry coupled to a slab ocean model to model the difference between the LMM and the period around 1780. During the LMM, the surface air temperature over the continents was colder and over some ocean areas warmer than 100 years later. The temperature signal could be shown to be related to a change in the AO (Arctic Oscillation)/NAO (North Atlantic Oscillation), which in turn is driven by variations in the meridional temperature gradient. This temperature pattern appears partly consistent with evidence from proxy data but too many large areas without adequate proxy data remain to draw definite conclusions on the agreement between simulation and observations.

The LMM was also included in 500-year-long transient runs of 


\section{5 - 1710 Temperature Difference from 1550 - 1800 Mean}
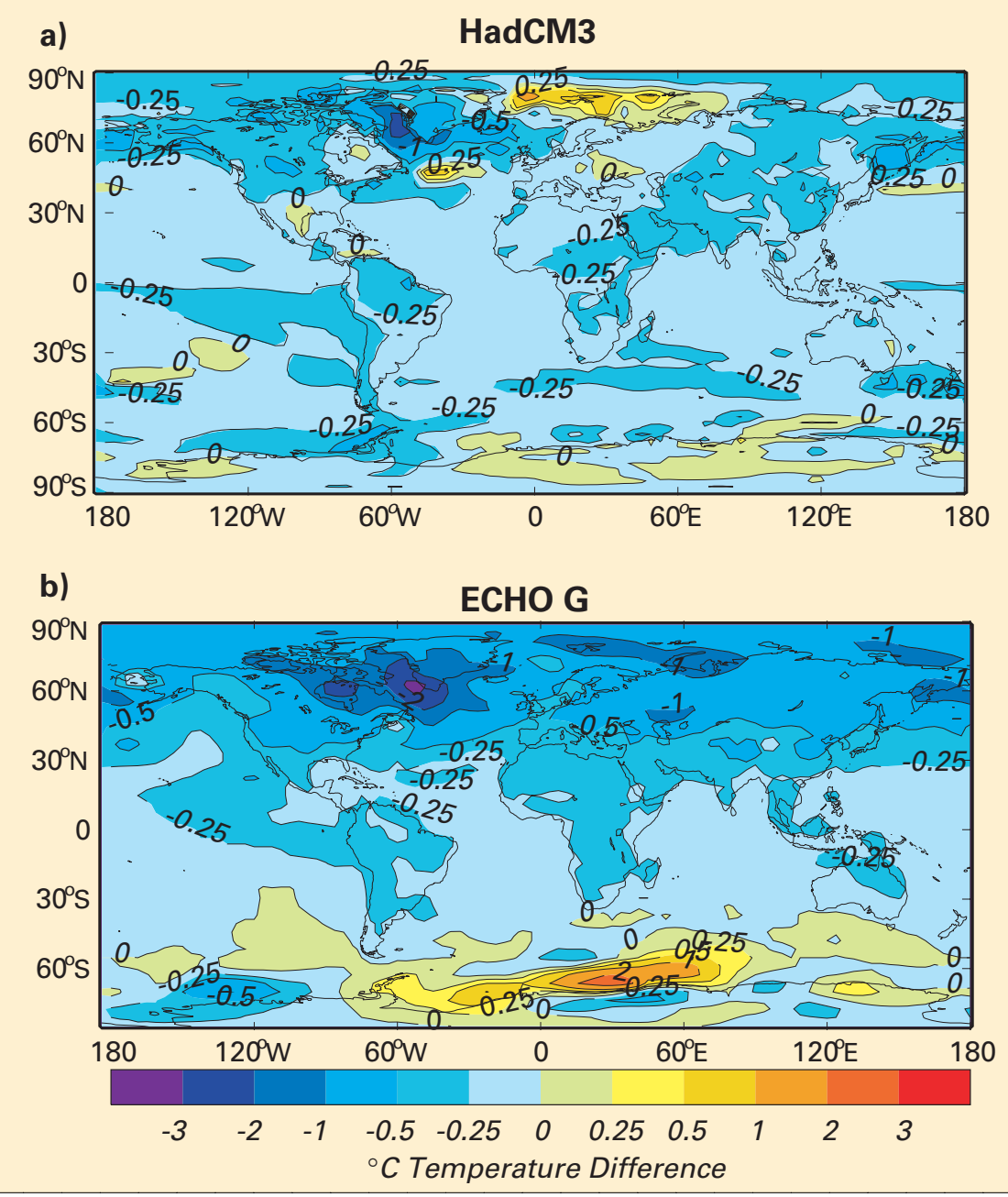

Figure 2: LMM cooling (1675-1710). Shown are changes in near-surface temperature from HadCM3 (a) and ECHO-G (b) for the 1675-1710 period minus the long-term average for 1550-1800. Contours are at $\pm 3,2,1,0.5,0.25$ and $0 \mathrm{~K}$. Global-average values are -0.21 and $-0.28 K$.

fully coupled atmosphere-ocean GCMs conducted by the GKSS Research Centre in collaboration with the MPI (ECHO-G, Fischer-Bruns et al. 2002, Zorita et al. 2003) and by UKMO (HadCM3). Preliminary results from both models show a clear global-mean cooling during the LMM and the DM (Fig. 1), which is of similar magnitude in both models. The ECHO-G simulation was forced with the major anthropogenic and natural forcings while the HadCM3 was only forced with natural forcings. Both groups are currently carrying out simulations with natural forcings only, and both natural and anthropogenic forcings, respectively. Note the increasing divergence between the two simulations from the mid-19th century as the simulated effect of anthropogenic forcings becomes more important. The cooling during the LMM has a spatial structure somewhat different from Shindell et al. (2001). Most noticeable is a strong cooling in the North-West Atlantic (Fig. 2), associated with increasing sea-ice extent in both simulations. Also apparent is a smaller cooling over Europe and other regions. In ECHO-G there is widespread cooling over the entire northern hemisphere with peak cooling to the west of Greenland of $-2 \mathrm{~K}$. By contrast, HadCM3, while still having a large amount of cooling to the west of Greenland manages to sustain a larger land-sea contrast than that of ECHO-G.

\section{Summary}

In this paper we have introduced the idea of simulating the climate of the last 500 to 1000 years. Pre- liminary results from two GCM simulations of the last 500 years demonstrate that it is now just about feasible to do this using state-of-the-art GCMs. This then provides a good opportunity to test both climate models and proxy data by comparison with one another and thus to better forecast anthropogenic climate change during this century. It also allows estimates to be made of the relative contribution of natural and anthropogenic climate forcings, and internal climate variability to total climate variability and change. A current European Union funded project called SOAP (http:

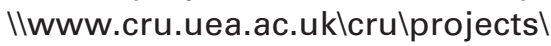
soap) aims to do this and bring together scientists working with paleodata with those working with models.

\section{ACKNOWLEDGEMENTS \\ SFBT was supported by the UK Govern- ment Met Research contract and, partly, by EU contract EVK2-CT-2002-00160 (SOAP), while computer time for the HadCM3 simulation was provided by the UK Dept. of Environment, Food and Rural Affairs PECD/37. The transient ECHO-G simulation has been part of the KIHZ project of the Helmholtz-Society. We are grateful to F.J. González-Rouco and E. Zorita, GKSS for providing the ECHO-G data.}

\section{REFERENCES}

Collins, M., Tett, S.F.B. and Cooper, C., 2001: The internal climate variability of $\mathrm{HadCM} 3$, a version of the Hadley Centre coupled model without flux adjustments. Climate Dynamics 17: 61-81.

Crowley, T.J., 2000: Causes of climate change over the past 1000 years. Science 289: 270-277.

Hall, A. and Stouffer, R.J., 2001: An Extreme Climate Event in a Coupled Ocean-Atmosphere Simulation without External Forcing. Nature 409: 171-174.

Shindell, D.T., Schmidt, G.A. Mann, M.E. Rind, D. and Waple, A., 2001: Solar forcing of regional climate change during the Maunder Minimum. Science 294: 2149-2152

Stott, P.A., Tett, S.F.B., Jones, G.S., Allen, M.R., Mitchell, J.F.B. and Jenkins, G.J., 2000: External control of 20th century temperature variations by natural and anthropogenic forcings. Science $\mathbf{1 5}$ : 2133-2137

Zorita E., von Storch, H., González-Rouco, F.J., Cubasch, U., Luterbacher, J., Legutke, S., FischerBruns, I. and Schlese, U., 2003: Simulation of the climate of the last five centuries. GKSS report 2003/12. (available from GKSS Research Centre, Library, D-21494 Geesthacht, Germany)

For full references please consult: www.pages-igbp.org/products/newsletters/ref2003_2.html 